\title{
XLVI. On oxalic acid. Communicated by Charles Hatchett, Esq., F.R.S.
}

\section{Thomas Thomson M.D. F.R.S. Ed.}

To cite this article: Thomas Thomson M.D. F.R.S. Ed. (1808) XLVI. On oxalic acid.

Communicated by Charles Hatchett, Esq., F.R.S. , Philosophical Magazine Series 1, 31:124, 244-253, DOI: $10.1080 / 14786440808563896$

To link to this article: http://dx.doi.org/10.1080/14786440808563896

册 Published online: 18 May 2009.

Submit your article to this journal $₫$

Џll Article views: 2

Q View related articles 5 
smallest have the same properties, and the thread may be seen to unfold with a good glass. By what means these threads are separated at the instant they are drawn from the spider's body, I am at a loss to determine, and by what kind of construction the aperture from whence they are drawn is contrived to spin a thread of a gummy consistence, either single or double, at the pleasure of the spider, is equally mysterious.

The spider, for some reason or other, is generally looked upon with abhorrence, and some have declared them to be poisonous, but the fact is otherwise ; they are perfectly innocent, which could be easily proved, and they are a very ingenious and wonderful little insect, highly deserving the attention of the curious. When $I$ say they are not venomous, I speak only of our English spiders ; for notwithstanding their dexterity in killing a $\mathrm{fly}$, there is, I believe, no doubt as to the means they use for that purpose, being commonly done by incisions made with thcir formidable forceps, and then sucking their blood.

There are many other very curious observations which might be made, peculiar to the spider, and which I may at a future period trouble you to insert in your valuable Magazine. $\quad \mathrm{I}$ am, sir, yours, \&c.

R. TEED.

XLVI. On Oxalic Acid. By Thomas Thomson, M.D. F.R.S. Ed. Communicated by Charles HatchetT, Esq., F.R.S.

[Continued from p. 111.]

\section{Decomposition of the Oxalates.}

1. $W_{\text {HEN oxalic acid, in the state of crystals, is exposed }}$ to heat, it is only partially acted upon, a considerable portion escaping without alteration; but when an alkaline or earthy oxalate is heated, the acid remains fixed till it undergoes complete decomposition. The new substances into which the acid is converted, as far as my experience goes, are always the same, what oxalate soever we employ. They 
are five in number ; namely, water, carlonic acid, carlonic oxide, carbureted hydrogen, and charcual.

2. The water is never quite pure. Though no sensible portion of oil can be perceived in it, yet it has always the peculiar smell of the water obtained during the distillation of wood; a smell which is usually ascribed to oil. It commonly shows traces of the presence of ammonia, changing vegetable blues to green, and smoking when brought near muriatic acid ; but this minute portion of ammonia is probably only accidentally present. All the oxalates which I decomposed by distillation, were obtained by double decomposition from oxalate of ammonia; and though they were washed with sufficient care, yet I think it not unlikely that a minute portion of oxalate of ammonia might continue to adhere. Practical chemists know the extreme difficulty of removing every trace of a salt with which another has been mixed.

The carbonic acid remains partly combined with the base, which always becomes a carbonate, and partly makes its escape in the form of gas.

The carbonic oxide and carbureted hydrogen make their escape in the form of gas : the charcoal remains in the retort mixed with the base, to which it communicates a gray colour: the quantity of it depends in some measure upon the heat. If the oxalate was exprosed to a very violent heat, no charcoal at all remains. Hence it probably acts upon the carbonic acid united to the base, converting it into carbonic oxide, as happens when a mixture of a carlsonate and charcoal is heated.

3. I was induced to examine this decomposition with considerable attention, because I conceived that it would furnish the means of estimating the composition of oxalic acid; and I pitched upon oxalate of lime, as the salt best adapted for the purpose I had in view. A determinate quantity of this salt was put into a small retort, and gradually heated to redness. This retort was connected with a pneumatic trough by means of a long glass tube, having a valve at its extremity which allowed gas to issue out, but 
prevented any watcr from entering the tube. The experiment was repeated three tines.

4. A hundred grains of oxalate of lime, when thus heated, yield above sixty cubic inches of a gas, which is always a mixture of carbonic acid and inflammable air, nearly in the proportion of one part of the former to three and a half of the latter, reckoning by bulk. The specific gravity of the inflammable gas was 0.908 , conmon air being 1.000 ; it burns with a blue flame, and when mixed with oxygen may be kindled by the electric spark. The loudness of the report depends upon the proportion of oxygen.

The smallest quantity of oxygen, with which it can be mixed, so as to burn by the electric spark, is $1-9$ th ; the combustion is very feeble, and is attended with no perceptible report. If the residue be washed in lime-water and mixed with l-9th of its bulk of oxygen, it may be kindled a second time : this may be repeated five times, after which the residue cannot be made to burn.

The combustion becomes more violent, and the report louder, as we increase the proportion of oxygen, and both are greatest when the oxygen is double the bulk of the gas. As we increase the dose of oxygen, the combustion becomes more and more fecble; and five parts of oxygen and one of gas is the limit of combustion on this side: for a mixture of six parts of oxygen and one of the inflammable air will not burn.

In these experiments the results differ materially from each other, when the proportion of oxygen used is small and when it is great. I am nol able at present to account for this difference, which holds not only with respect to this gas, but every compound inflammable gas which I have examined. This difference makes it impossible to use both extremes of the series: I make choice of that in which the proportion of oxygen is considerable, as upon the whole more satisfactory. The best proportion is one part of the gas and iwo parts of oxygen. The oxygen ought not to be pure, but diluted with at least the third of its bulk of azote, unless the gas be much contaminated with common air. 
I have elsewhere detailed the method which I follow in analysing gases of this nature*. The following table exhibits the mean of a considerable number of trials of this gas with oxygen.

\begin{tabular}{|c|c|c|c|}
\hline $\begin{array}{c}\text { Measures of } \\
\text { inflammable Air } \\
\text { consumed. }\end{array}$ & $\begin{array}{c}\text { Measures of } \\
\text { Oxygen } \\
\text { consumed. }\end{array}$ & $\begin{array}{c}\text { Carbonic Acid } \\
\text { formed. }\end{array}$ & $\begin{array}{c}\text { Diminution } \\
\text { of Bulk. }\end{array}$ \\
\hline 100 & 91 & 93 & 98 \\
\hline
\end{tabular}

that is to say, 100 cubic inches of the gas when burnt, combine with $9 \mathrm{~J}$ cubic inches of oxygen; there are produced 93 inches of carbonic acid; and after the combustion these 93 inches alone remain, the rest being condensed. Hence we conclude that the other substance produced was water.

This result corresponds almost exactly with what would have been obtained, if we had made the same experiment upon a mixture of 70 measures of carbonic oxide, and 30 measures of carbureted hydrogen, as will appear from the following table.

\begin{tabular}{|r|c|c|c|c|}
\hline & $\begin{array}{c}\text { Measures of } \\
\text { inflammable } \\
\text { Gas con- } \\
\text { sumed }\end{array}$ & $\begin{array}{c}\text { Measures of } \\
\text { Oxygen } \\
\text { consimed. }\end{array}$ & $\begin{array}{c}\text { Measures of } \\
\text { carbonic } \\
\text { Acid formed }\end{array}$ & $\begin{array}{c}\text { Diminution } \\
\text { of Bulk. }\end{array}$ \\
\hline $\begin{array}{l}\text { Carbonic oxide } \\
\text { Carbureted hy- } \\
\text { drogen }\end{array}$ & 70 & 31.5 & 63 & 38.5 \\
\hline Total & 100 & 91.5 & 03 & 98.5 \\
\hline
\end{tabular}

This coincidence is so exact, that I do not hesitate to conclude that the inflammable gas, which was the subject of experiment, was in reality a mixture of 70 parts of carbonic oxide, and 30 of carbureted hydrogen. The specific gravity indeed, which was 0.908 , does not exactly agree with the specific gravity of such a mixture ; for $2 \frac{1}{3}$ measures of carbonic oxide, and one measure of carbureted hydrogen, ought

* See Nicholson's Journal, xvi. 247.

Q 4 to 
to form a mixture of the specific gravity 0.849 , provided the specific gravity of carbonic oxide be 0.956 , and that of carbureted hydrogen 0.600 ; but this objection cannot be admitted to be of much weight, till the specific gravity of pure carbureted hydrogen be ascertained with more accuracy than has hitberto been done.

The results contained in the preceding table enable us to determine the composition of this inflammable air with considerable precision; for 100 cubic inches of it require 91 inches of oxygen, and form 93 cubic inches of carbonic acid. But it is known that carbonic acid gas requires for its formation a quantity of oxygen gas equal to its own bulk: therefore to form 93 inches of it, 93 inches of oxygen gas must have been employed; but only 91 were mixed with the gas: therefore the gas itself must have furnislied a quantity of oxygen, equivalent to the bulk of two cubic inches, besides all the carbon contained in 93 inches of carbonic acid.

This carbon amounts in weight to 12.09 grains.

Two cubic inches of oxygen weigh $\quad \cdot 68$

$$
\text { Total } \overline{12 \cdot 77}
$$

But as 100 cubic inches of the gas weigh $28 \cdot 15$ grains, it is obvious that besides the $12 \cdot 77$ grains which it furnished to the carbonic acid, it must have contained 15.38 grains of additional matter; but as the only two products were carbonic acid and water, it is plain that the whole of this additional matter must, by the explosion, have been converted into water. Its constituents of course must have been

$$
\begin{aligned}
& 13 \cdot 19 \text { oxygen } \\
& 2 \cdot 19 \text { hydrogen }
\end{aligned}
$$

$15 \cdot 38$

Adding this to the $12 \cdot 77$ grains formerly obtained, we get the composition of the gas as follows:

\begin{tabular}{lr} 
Oxygen & $13 \cdot 87$ \\
Carbon & $12 \cdot 09$ \\
Hydrogen & 2.19 \\
\hline & $28 \cdot 15$ \\
\hline
\end{tabular}


which reduced to 100 parts, becomes

\begin{tabular}{lr} 
Oxygen & 49.27 \\
Carbon & 42.95 \\
Hydrogen & 7.78 \\
\hline & $100 \cdot 00$ \\
\hline
\end{tabular}

5. The residue which remained in the retort, after the distillation was over, was a gray powder, not unlike pounded clay slate. To ascertain its constituents, it was dissolved in diluted nitric acid with the nccessary precautions; the loss of weight indicated the quantity of carbonic acid. The charcoal remaining undissolved, was allowed to subside, carefully washed by repeated affusions of water, and then dried in a glass or porcelain capsule. It must not be separated by the filter, for it adheres so obstinately that it cannot be taken off the paper, nor weighed. The nitric acid solution was precipitated by carbonate of soda, and the carbonate of lime obtained was violently heated in a platinum crucible. What remained was pure lime.

6. I shall now detail one of my experiments more particularly. Eighty-nine grains of well dried oxalate of lime were exposed in a small retort to a heat gradually raised to redness; the products were the following:

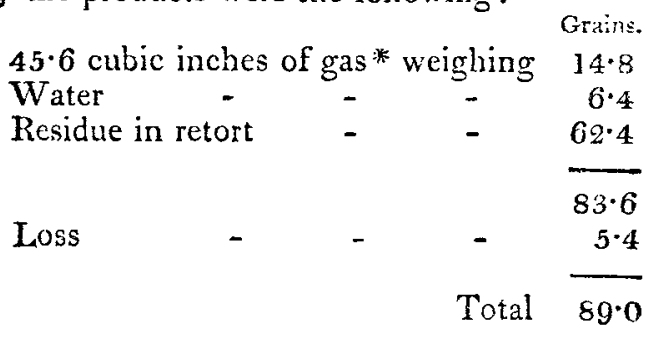

The loss is obviously owing to the gas which filled the retort and tube when the experiment was concluded. We are warranted therefore to add it to the weight of the gaseous products obtained.

* The gas obtained measured 60 cubic inches, but 144 inches of these were found to be common air which had previously filled the retort and tube; this quantity was therefore deducted. 
Now the gas was composed of

Carbonic acid $\quad 10.5$ cubic inches $=4.9$ grains. Inflammable air $35.1 \quad-\quad=9.9$

so that one-third of the weight was carbonic acid, and twothirds inflammable air. If we divide the 5.4 grains of loss, in that proportion we obtain 1.8 grains carbonic acid, and 3.6 grains of inflammable air. Adding these quantities to the weight obtained, we get for the weight of the whole gaseous product

Grains.

Carbonic acid $6 \cdot 7$

Inflammable air 13.5

$20 \cdot 2$

The 62.4 grains of residue in the retort were composed of

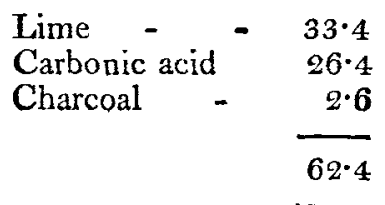

Now it is clear, that the 89 grains of oxalate of lime were composed of

$$
\begin{aligned}
& \text { Lime - - } 33.4 \\
& \text { Acid - } \quad 55.6 \\
& 89 \cdot 0
\end{aligned}
$$

The acid was completely decomposed and resolved into the following products:

$$
\begin{array}{lr}
\text { Carbonic acid } & \mathbf{3 3 \cdot 1} \\
\text { Inflammable air } & 13.5 \\
\text { Water - } & 6 \cdot 4 \\
\text { Charcoal } & -\quad 2.6 \\
\hline & \\
\hline 55.6
\end{array}
$$

Had the experiment been made upon 100 grains of oxalic acid instcad of $55 \cdot 6$, it is clear that the proportions would have been as follows: 


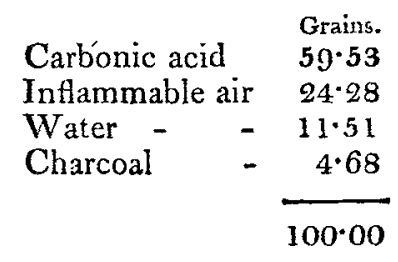

The most remarkable circumstance attending the decomposition of oxalic acid by heat, is the great proportion of carbonic acid formed; the quantity amounts to 6-10ths of the whole weight of acid clecomposed.

As the composition of all these products of oxalic acid is known with considerable accuracy, it is obvious that they furnish us with the means of ascertaining the constituents of that acid itself.

59.53 grains of carbonic acid are composed of

$$
\begin{aligned}
& \text { Oxygen } \\
& \text { Carbon }
\end{aligned}
$$

24.28 grains of inflammable air, according to the analysis given in a preceding part of this paper, are composed of

$$
\begin{array}{llr}
\text { Oxygen } & - & 11.96 \\
\text { Carbon } & - & 10 \cdot 43 \\
\text { Hydrogen } & - & 1.89 \\
\hline & & 24 \cdot 28
\end{array}
$$

11.51 grains of water are composed of

$$
\begin{aligned}
& \text { Oxygen - } 9.87 \\
& \text { Hydrogen - } \quad 1.64 \\
& 11.51
\end{aligned}
$$

As for the charcoal, though it probably contains both oxygen and hydrogen as well as carbon, yet as the proportion of the two first ingredients is probably very small, and as we have no means of estimating them, we must at present rest satisfied with considering it as composed of pure carbon.

When 
When these different elements are collected under their proper heads, we obtain

$$
\begin{aligned}
& \text { 1. Oxygen in carbonic acid } \quad 42.86 \\
& \text { - - inflammable air } \quad 11.96 \\
& \text { - - water - - } 9.87 \\
& 64 \cdot 69 \\
& \text { 2. Carbon in carbonic acid } 16.67 \\
& \text { - _ inflammable air } 10 \cdot 43 \\
& \text { - - charcoal - } 4 \cdot 68 \\
& \text { 3. Hydrogen in inflammable air } \frac{31.78}{1.89} \\
& - \text { - water - - } \frac{1.64}{3.53} \\
& \text { Hence oxalic acid is composed of oxygen } 64 \cdot 69 \\
& \text { - - _ - - carbon } 31.78 \\
& \text { - - - - - - hydrogen } 3.53 \\
& 100 \cdot 00
\end{aligned}
$$

7. The result of two other cxperiments on oxalate of lime was very nearly the same as the precerling. The following may be stated in round numbers as the mean of the whole. Oxalic acid is a compround of

$$
\begin{aligned}
& \text { Oxygen - } 64 \\
& \text { Carbon - } 32 \\
& \text { Hydrogen - } 4 \\
& 300
\end{aligned}
$$

8. The only other analysis of oxalic acid with which I am acquainted has been given by $M$. Fourcroy, as the result of his own experiments, in conjunction with those of Vauquelin*. It is as follows:

\footnotetext{
* Sysieme de Connois. Chem. vii. 224.
} 


\begin{tabular}{llc} 
Oxygen & - & Grains. \\
Carbon & - & 13 \\
Hydrugen & - & 10 \\
\hline 100
\end{tabular}

It gave me considerable uneasiness to observe, that my experiments led to conclusions irreconcileable with those of chemists of such eminence and consummate skill, and it. was not without considerable hesitation that $I$ ventured to place any reliance upon them. I am persuaded, however, that some mistaize has inadvertently insinuated itself into their calculations; since the carbonic acid alone, formed during the distillation of oxalate of lime, contains considerably more carbon than the whole quantity which they assign to the oxalic acid decomposed. M. Fourcroy informs us, that oxalic acid is converted into carbonic acid and water, when acted upon by hot nitric acid; and this decomposition seems to have been the method employed to ascertain the proportion of the constituents of oxalic acid; but the numbers assigned by him do not correspond with this statement. For 10 parts of hydrogen require 60 of oxygen to convert them into water, and 13 of carbon require at least 33 of oxygen. So that instead of 77 parts of oxygen, there would have been required no less than 98 to convert the hydrogen and carbon into water and carbonic acid. It is true, that the surplus of oxygen may be conceived to be furnished by the nitric acid; but if this be admitted (and I have no doubt from experience that the nitric acid actually does communicate oxygen), it is difficult to see how the constituents of oxalic acid could be determined by any such decomposition, unless the.quantity of oxygen furnished by the nitric acid were accurately asccrtained.

[To be continued.] 